\title{
The basics of biocontainment
}

\author{
Studying potentially dangerous microbes in animal models of the disease they cause takes some extra considerations, \\ as researchers and staff must perform their work under the careful restrictions of different biosafety level laboratories.
}

\section{Jim Kling}

l: n early 2020, when the first concerns arose about a SARS-CoV-2 pandemic, researchers at biosafety facilities realized they would soon be pivoting to work with the novel coronavirus. Fortunately, many had previous experience to draw on, such as working with influenza virus or other airborne pathogens, or with SARS-CoV-1. That 2002 outbreak resulted in a more severe, though less transmissible, disease than the current virus.

Preprints from Chinese and Asian researchers guided early efforts, said Kenneth Palmer, director of the University of Louisville (UoL) Regional Biocontainment Laboratory and the UofL Center for Predictive Medicine for Biodefense and Emerging Infectious Diseases. The team in Kentucky had also established a ferret model during their work with SARS-CoV-1. "We found that our experience with the ferret model of SARS-CoV-1 was very similar to the published experience [with SARS-CoV-2], and the procedures we are using for research are very similar between SARS-CoV1 and SARS-CoV2, and avian influenza virus," said Palmer.

But whether a virus is entirely novel or has some semblance to pathogens of prior outbreaks, there are two essentials: "How is it transmitted, and how do we kill it?" said Brian O'Shea, biological safety program manager at Battelle's Biomedical Research Center.

Answering those questions takes some extra effort and preparations. 'Biocontainment' is often the stuff of science fiction and zombie apocalypses, but in real life it plays a central role in biomedical research. "Under normal circumstances, for potential biowarfare agents, we're hoping we're testing products that will sit in the strategic national stockpile and collect dust," said Dan Sanford, a senior research leader at Battelle.

Active pandemics can up the ante, but the basics of biocontainment remain the same.

\section{To the biosafety lab}

The first critical decision to be made with any new pathogen is what level of containment it will require. Biosafety labs
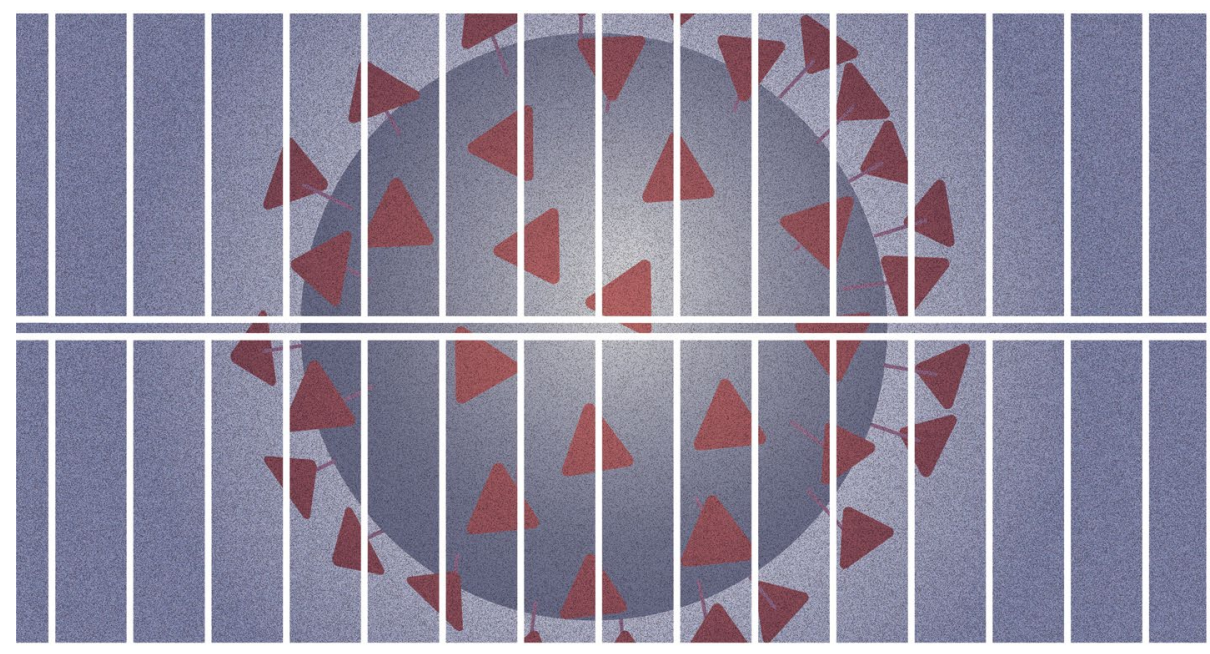

Keeping microbes, such as SARS-CoV-2, contained is a critical consideration for those studying dangerous agents in biosafety facilities. Credit: E. Dewalt, Springer Nature

are tiered from biosafety level (BSL) 1 to 4. BSL-1 can be used for agents that don't consistently cause disease. Work can be done on open benches, and little personal protective equipment (PPE) is required, though the lab is separated from the rest of the facility. BSL-2 labs work with moderately hazardous agents such as Staphylococcus aureus, a common cause of skin and other infections. PPE use is still minimal, but the work occurs behind self-closing doors and animals are often handled in biosafety cabinets, which are enclosed, ventilated workspaces with a sash that can also be used to house the cages; this ensures those animals share the same exposure status and environmental conditions.

Things start to get interesting at level 3. BSL-3 facilities are designed to house potentially lethal, airborne microbes. The bacteria that causes tuberculosis is one example, as is the virus behind avian influenza. Two sets of doors isolate a BSL-3 lab. If a vaccine exists, staff may be required to be immunized against the microbe being studied within and they should wear PPE as well as respirators. All work is done within biosafety cabinets, and the air must be filtered before it's exhausted. BSL- 4 facilities are reserved for agents with a high fatality rate, such as Ebola. They require full body positive pressure suits, decontamination of all materials, and a shower upon exiting the lab. Work is performed in a biosafety cabinet, and the lab is housed in a completely separate building (Table 1).

SARS-CoV-2 falls into the BSL-3 category. The Centers for Disease Control has not classified it as a select agent - that is, a microbe with the potential to be used in biowarfare or as a terrorist weapon. The pandemic has made the designation moot, according to O'Shea: "It's not hard for someone to get hold of." Still, Battelle carefully tracks its viral samples to select agent standards, just in case that designation should change.

BSL facilities come in a range of sizes. The Battelle BSL-3 facility is fairly large, with 16 holding rooms and 3 rooms reserved for challenges and other procedures, along with associated microbiology wet labs. It is all connected within one building today, though it started out as individual units. "It was built up like a Lego ${ }^{\mathrm{m}}$ set over time as research demanded," said O'Shea. The BSL-3 facility is connected to supporting BSL-2 labs via airlocks, where animals may be 


\begin{tabular}{|c|c|c|c|c|}
\hline & BSL-1 & BSL-2 & BSL-3 & BSL-4 \\
\hline Use & $\begin{array}{l}\text { For studying microbes that don't } \\
\text { consistently cause disease }\end{array}$ & $\begin{array}{l}\text { For studying moderately } \\
\text { hazardous microbes }\end{array}$ & $\begin{array}{l}\text { For studying potentially lethal, } \\
\text { airborne microbes }\end{array}$ & For studying highly lethal microbes \\
\hline $\begin{array}{l}\text { Example } \\
\text { microbes }\end{array}$ & $\begin{array}{l}\text { Non-pathogenic Escherichia coli, } \\
\text { Saccharomyces cerevisiae }\end{array}$ & $\begin{array}{l}\text { Staphylococcus aureus; } \\
\text { Hepatitis viruses }\end{array}$ & $\begin{array}{l}\text { Mycobacterium tuberculosis; } \\
\text { SARS-CoV-2 }\end{array}$ & Ebola virus; Lassa virus \\
\hline $\begin{array}{l}\text { Containment } \\
\text { measures }\end{array}$ & $\begin{array}{l}\text { Basic safety measures, but } \\
\text { open benches and no special } \\
\text { equipment required }\end{array}$ & $\begin{array}{l}\text { Controlled access; } \\
\text { PPE worn and biosafety } \\
\text { cabinets used for } \\
\text { containment }\end{array}$ & $\begin{array}{l}\text { Double-door isolation; biosafety } \\
\text { cabinets \& air filtration required; } \\
\text { PPE and respirators worn; } \\
\text { decontamination measures } \\
\text { taken }\end{array}$ & $\begin{array}{l}\text { Housed in entirely separate buildings, } \\
\text { with air filtration; biosafety cabinets } \\
\text { required; staff wear full body, positive } \\
\text { pressure suits; decontamination } \\
\text { measures taken }\end{array}$ \\
\hline
\end{tabular}

kept before they are exposed to an agent or vaccine. The BSL-2 lab reduces the burden on the more sensitive BSL-3 area. "If you don't need to work inside the BSL-3, then we don't want you to be back there. There are support facilities all over the place, but the BSL-3 is centrally housed," he added.

Within the labs themselves, the animal cages are a vital component of the unit. They must meet regulatory standards for housing the animal, but also minimize risk to the handlers. Some cages are closed systems, with air that is filtered before entry and then exhausted. That prevents infected animals from prematurely exposing vaccinated or control animals.

Engineering caging systems can be tricky. Brian Bilecki, director of Vivarium Design Services at Allentown, Inc, described one system that he helped develop, which used latches and compression gaskets to maintain seals. Users must dock and undock the cage from racks in order to clean it or work with the animals. While developing the system, the team used tracer gas to test whether the cage was completely evacuated of air before a user opened it. "We found a small burst of contaminated air inside the cage at one of the ports in the back," said Bilecki. That prompted a change. "We redesigned the ports and interface such that the last thing to close was the exhaust on the rack, so that was evacuated before the cage was disengaged. That's the level of concern with these types of products," he said.

Design is also critical for experimental set ups. To investigate how transmissible SARS-CoV-2 is in physical spaces, such as indoor restaurants, researchers are using ferrets to work out how long it takes for one animal to infect another, and even how much virus needs to be expelled to raise the infection risk. A typical setup for a transmission experiment would be six large cages that are enclosed together around a central enclosed space, or plenum. Airflow comes from the sides, through the cages, and then out the center plenum where it is exhausted into the building's outflow.
The cages are all wire, similar to a pet store or home cage, with a perforated plastic floor and a pan underneath to catch feces and urine. A sealed plexiglass wall and door surround the entire system, which rests inside the BSL-3 facility.

To test infectivity, researchers insert dividers to partition each cage, placing infected animals on the outside, where the fresh air flows in. The naïve animal is on the inside of the system, closer to the plenum and outflow. It's critical to avoid physical contact between the animals, to ensure that any infection occurs through respiration. Despite their apparent simplicity, these structures pose engineering challenges, according to Bilecki. Any object that reduces airflow, like a divider, can cause suspended droplets to fall out of the air and on to surfaces. "I have to manage all of that, keeping the physical separation, and still have enough bioload to get that naïve animal to test the transmission that the researcher is looking for," said Bilecki.

Aside from the rooms and animal cages, respirators are key to working with airborne pathogens in BSL-3 and BSL-4 facilities. Two types of respirators are commonly used in BSL-3 facilities for studying SARS-CoV-2: N95 masks and powered air-purifying respirators (PAPRs). The latter has a breathing tube, and a battery-operated blower that draws in air and moves it through a high-efficiency particulate air (HEPA) filter to a full or half face-piece. Due to the pandemic, the shortage of N95 masks has led Battelle to move to PAPRs for some procedures, since the devices can be readily decontaminated multiple times.

As PPE became increasingly short in the spring of 2020 due to the pandemic, there were delays in some shipments that had the potential to delay research. "When we have a standard operating procedure in place that employs a certain type of PPE, and we can no longer get that PPE, we need to reevaluate our risk assessment for that procedure, or find some kind of augmented
PPE to keep that risk level low so that our staff can still work safely with the animals," said O'Shea. For example, in some cases the team decided it was safe to substitute boot covers for shoe covers. In other cases, a brand of safety equipment that the lab had long used might be sold out, forcing a switch. "We need to analyze that alternative to make sure it meets our standards as well," O'Shea added.

"We haven't gotten to a point where we've said: 'We can't do this procedure,' because there is some variability in the PPE we can use,' said O'Shea. "It's just one of the things we've had to deal with."

\section{Reward in risky environments}

Insufficient PPE or other failures could lead to exposure. Equipment can fail. The University of Louisville staff undergoes training to ensure workers react appropriately. "For training purposes, we would take out somebody's [respirator] battery and see how they respond to that situation, to make sure they don't get scared and take it off. So the staff are familiar with how to respond if something goes wrong," said Jennifer Kraenzle, manager of the Biocontainment Animal Facility at the University of Louisville.

The highest risk procedures involve direct handling of a biological agent in high concentration, such as challenging an animal with agent in a syringe or nebulizer. "Any direct interaction with a challenged, awake, alert animal - we want to limit the direct interaction between an animal care technician and a challenged animal because they're unpredictable. They could bite, they could scratch, they could shed virus or other organisms, and we really want a barrier between the animal and the technician," said O'Shea.

Generally speaking, animals are anesthetized when possible during such procedures. "When we're using high concentrated material, we make sure the animal is not moving and there's less risk to the staff," said Sanford. 
"The biggest risk is when you're handling the cages. Always," said Bilecki. When it's time for cleaning, for example, handlers move the animal to a clean cage, then remove contaminated bedding before sterilizing the cage. But does the exterior of the cage need to be wiped down? What about contamination in the drinking water?

All of those factors and more underline the human element of working a biocontainment facility. In 2014, the National Institutes of Health put in place a moratorium on gain-of-function experiments on influenza, SARS-CoV-1 (known simply as SARS-CoV at the time), and Middle East respiratory syndrome coronavirus (MERS). Such experiments aim to introduce changes to the virus in order to better understand its mode of transmission or infectivity. But several incidents involving mishandling of $\mathrm{H} 5 \mathrm{~N} 1$ influenza and smallpox samples unnerved some, leading to the pause. The moratorium was lifted in 2017, and research proposals are now evaluated by an NIH committee that determines if the experiments are really necessary, or if the same information could be gained through less risky means.

Bilecki echoes those concerns about safe handling. He makes his living designing cages with the lowest possible risk to staff and researchers, but he knows his work could be undermined by sloppy practice. "The honest truth is that all the mechanical systems in the world that we can design, without really solid training and standard operating procedures for everyone to follow, you can throw that out the window. It has to be a very regimented day when you're in a space like that," said Bilecki.

"It takes a lot of organization, a lot of planning, just to do a simple task in a high containment lab. That makes the standard operating procedures we have very important. If one thing is forgotten or mistaken, it can cause a cascade effect in the research," said Sanford.

Indeed, the work environment in a BSL-3 or BSL-4 requires a special kind of individual. "There is no tolerance for going off protocol. It's best suited to people who are very rigorous and meticulous," said Palmer. Researchers and staff start out working in BSL-2 and must first demonstrate proficiency in that lower risk environment. "It's sort of a tiered experience, so it selects for people who are well suited to working in a very regulated environment," he said.

The extra layers of security and protection mean that everything moves at a slower pace. "It takes a lot longer to do routine maintenance. A cage change at animal BSL- 2 might take 2 or 3 minutes, where in the animal BSL-3 it might take 6-10 minutes," said Karen Powell, supervisor of the Large Animal Clinical Services and Regional Biocontainment Laboratory at the University of Louisville.

It's also vital that researchers and staff come prepared. "If you have to move backwards into the hall, maybe because you need biohazard bags or some kind of supplies, it might take five or six minutes just to get through the doors because you have to wait for interlocks. Everything just takes a tremendous amount of additional time," she said.

"You learn very quickly to be very organized before you go into the facility," added Kraenzle, who said she enjoys working in biocontainment despite the challenges. "Everything is in your control, it's very black and white with no grey area. I like that, it's definitive. It has a different feel [than other animal work]: very slow, very methodical. I like that in a work environment," she said.

The intense attention to detail can be difficult to keep up for long periods, so workers at Battelle are given regimented breaks. Workflow management among staff is also an important consideration. "It's not something you want to do for nine or 10 consecutive hours. Staff go in, do their morning activities, then come out and get a break, some water or food, and then go back," said Sanford.

But the work is rewarding, said Sanford, because of the high probability of the research having a direct impact on public health. He recalled his days in graduate school, working to understand the function of a gene involved in tumor cells. If it ever became the target of a drug, he figured he would never know about it because pharmaceutical companies often keep that information proprietary. "But especially on the animal side, we're testing counter-measures. Knowing that you had a hand in evaluating products that in an emergency could be deployed and you've shown to be efficacious, it's very rewarding. The technicians who understand that generally do better. They're very focused on their specific task, but at the end of the study they love to see the big picture," said Sanford.

Jim Kling $\bowtie$

Freelance science writer, Bellingham, WA, USA.

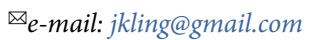

Published online: 9 September 2020 https://doi.org/10.1038/s41684-020-0644-8 